\title{
O desentendimento como característica inerente à democracia
}

\section{Disagreement as an inherent characteristic of democracy}

\author{
VALMIR GONÇALEZ DOS SANTOS
}

\begin{abstract}
Resumo: O artigo busca propiciar reflexões sobre a jovem democracia brasileira, pensada aqui sob à luz da excêntrica filosofia de Rancière. Se considerarmos os tempos da República brasileira, constatamos que os períodos democráticos são breves e sempre sofreram ameaças. Há três décadas vivemos em um regime democrático que, no entanto, ainda é frágil. Do ponto de vista histórico, a democracia brasileira é jovem e continua sendo construída sob ameaças, sua vigência carece de vigilância constante, pois, de vários lados, há forças que a fragilizam, especialmente aquelas que proclamam a ordem e o consenso. $\mathrm{O}$ que tais forças querem, ainda que digam falar em nome da democracia, é a organização da vida e do poder de um modo hierárquico e o esvaziamento dos espaços públicos que, necessariamente, são conflituosos e orientados por uma racionalidade dissensual. Para essa comunicação, perguntamo-nos se, no entanto, essa fragilidade da jovem democracia brasileira não é, justamente, característica da própria democracia, desde a sua invenção na Grécia. Trata-se, pois, de pensar, outra vez, quais são os sentidos disso que chamamos de democracia, regime político no qual o povo detém o poder. Jacques Rancière desenvolve uma perspectiva excêntrica acerca da democracia e nos mostra que desde o seu surgimento ela foi alvo de ódio e sempre está em risco, daí ele escrever um livro intitulado Ódio à democracia (2014). Esta perspectiva nos interessa, na medida em que se situa a contrapelo do que se consensuou entender por democracia e por política como a mera organização da vida coletiva. A partir da filosofia de Rancière, procura-se, então, resgatar o que é próprio de uma investigação filosófica acerca da política, abordando em que âmbito e quando esta existe e mostrando que, inúmeras vezes, ela se confunde com polícia; o que implicará trazer à tona o que Rancière diz ser fundamental para a existência da política e da democracia, a saber, a lógica do desentendimento.
\end{abstract}

Palavras-chave: Democracia. Política. Desentendimento. Polícia.

Abstract: The article seeks to provide reflections on the young Brazilian democracy, thought here in the light of the eccentric philosophy of Rancière. If we consider the times of the Brazilian Republic, we find that democratic periods are brief and have always been threatened. For three decades we have lived in a democratic regime which, however, is still fragile. From a historical point of view, Brazilian democracy is young and continues to be built under threat, its validity is not constantly monitored, because there are forces that weaken it, especially those that proclaim order and consensus. What these forces want, even if they speak in the name of democracy, is the organization of life and power in a hierarchical way and the emptying of public spaces that are necessarily conflictive and oriented by a dissensual rationality. For this communication, we wonder if, however, this fragility of the young Brazilian democracy is not exactly characteristic of democracy itself, since its invention in Greece. It is therefore a matter of thinking, again, what are the meanings of what we call democracy, a political regime in which the people hold power. Jacques Rancière develops an eccentric perspective on democracy and shows us that since his emergence he has been a target of hatred and is always at risk, hence he wrote a book entitled Hating Democracy (2014). This perspective interests us, as it is situated against the grain of what has been agreed to be understood by democracy and politics as the mere organization of collective life. From the philosophy of Rancière, it is sought, then, to rescue what is proper to a philosophical investigation about politics, addressing in what scope and

\footnotetext{
${ }^{1}$ Graduado e Mestre em Filosofia pela UNIOESTE. E-mail: valmir_1osantos@hotmail.com.
} 
when it exists and showing that, on many occasions, it confuses itself with police; which implies bringing up what Rancière says is fundamental to the existence of politics and democracy, namely, the logic of misunderstanding.

Keywords: Democracy. Politics. Disagreement. Police.Resumo em língua estrangeira.

\section{Introdução}

Trata-se, nesse texto, de analisar o que comumente chamamos de democracia, o tal governo do povo, sob a luz da excêntrica filosofia de Jacques Rancière. Se considerarmos os tempos da República brasileira, por exemplo, constatamos que os períodos democráticos são breves e sempre sofreram ameaças. Há três décadas vivemos em um regime democrático que, no entanto, ainda é frágil. Do ponto de vista histórico, a democracia brasileira é jovem e continua sendo construída sob ameaças, sua vigência carece de vigilância constante, pois, de vários lados, há forças que a fragilizam, especialmente aquelas que proclamam a ordem e o consenso. $O$ que tais forças querem, ainda que digam falar em nome da democracia, é a organização da vida e do poder de um modo hierárquico e o esvaziamento dos espaços públicos que, necessariamente, são conflituosos e orientados por uma racionalidade dissensual.

Para esse texto, perguntamo-nos se, no entanto, essa fragilidade da jovem democracia brasileira não é, justamente, característica da própria democracia, desde a sua invenção na Grécia. Trata-se, pois, de pensar, outra vez, quais são os sentidos disso que chamamos de democracia, regime político no qual o povo detém o poder. Rancière desenvolve uma perspectiva excêntrica acerca da democracia e nos mostra que desde o seu surgimento ela foi alvo de ódio e sempre está em risco. Esta perspectiva nos interessa, na medida em que se situa a contrapelo do que se consensuou entender por democracia e por política como a mera organização da vida coletiva. A partir da filosofia de Rancière, procura-se, então, resgatar o que é próprio de uma investigação filosófica acerca da política, abordando em que âmbito e quando esta existe e mostrando que, inúmeras vezes, ela se confunde com polícia; o que implicará trazer à tona o que Rancière diz ser fundamental para a existência da política e da democracia, a saber, a lógica do desentendimento.

Começamos, então, pelo início disso que denominou-se democracia. Etimologicamente o conceito de democracia (Demokratía), criado a partir dos prefixos demos, "povo”, e kratos, "poder", significa "governo do povo". Desde sua origem, a democracia na Grécia não estava orientada por uma completa igualdade entre todos os indivíduos. Outra questão que vale lembrar também, é que "demokratia era utilizada por seus críticos aristocratas como uma espécie de epiteto, para mostrar seu despreza pelas pessoas comuns que haviam usurpado o controle que os aristocratas tinham sobre o governo". (DAHL, 2001, p. 20). 
De início, na democracia ateniense faziam parte apenas àqueles que eram considerados cidadãos, indivíduos livres e iguais. Ficavam fora dessa conta os escravos, os estrangeiros, as mulheres e as crianças. Ou seja, participavam apenas da democracia, uma parte minoritária que deveria ser nascida na polis, ser homem e maior de 18 anos, isso sem contar que deveria ser filho de quem participava da política (Cf. CHAUÍ, 200o). A justificativa para ter pessoas aptas a participarem ou não da democracia se dava pelo fato de que os gregos defendiam que aqueles que não compartilhavam dos mesmos costumes da polis não poderiam ter a compreensão necessária para escolher o que era melhor para a mesma. Imediatamente se percebe que a ideia de igualdade que orientava a democracia era bastante restritiva e excludente.

O preparo intelectual que faltava aos escravos era o logos, a fala. Os escravos, eram tidos como seres que não o possuíam, eram dotados apenas de voz, o que todos os outros animais também possuem, na medida em que são capazes de mostrar contentamento e desgosto. Essa era, então, uma das justificativas para manter uma relação desigual entre homens livres e escravos, os primeiros tinham ou possuíam logos, a capacidade de falar, e outros não. Segundo os gregos, aqueles que possuíam o logos eram capazes de julgar, muito mais do que apenas mostrar contentamento ou desgosto. Essa diferença entre possuidores de logos e não possuidores é tremenda. É por meio da palavra que o homem consegue e pode viver em comunidade. Segundo Aristóteles, a palavra possui significações, e com ela o homem pode decidir sobre o justo e o injusto, algo impossível para os incapazes de falar. Assim, a exclusão da maior parte dos habitantes da cidade estava justificada por uma incapacidade ${ }^{2}$.

É apenas pelo uso do logos, manifestado pela fala, que o homem consegue viver em conjunto, mostrar suas inquietações e resolver problemas. Com respeito à fala, Aristóteles argumenta:

\footnotetext{
${ }^{2}$ Walter Kohan, em Infância e educação em Platão, ao tratar da etimologia de "infantil", mostra a importância da fala dada pelos gregos e justifica, etimologicamente, o uso abrangente da denominação de infantil para os incapazes: "Infans está formado por um prefixo privativo in e fari, 'falar', dali seu sentido de "que não fala", "incapaz de falar". Tão forte é seu sentido originário que Lucrécio emprega ainda o substantivo derivado infantia com o sentido de "incapacidade de falar". Mas logo infans - substantivado - e infantia são empregados no sentido de "infante", "criança" e "infância", respectivamente. Desse sentido surgem vários derivados e compostos, na época imperial, como infantilis, "infantil" e infanticidium, "infanticídio". Quintiliano (I, 1,18$)$ fixa a idade em que a criança é considerada como incapaz de falar até por volta dos sete anos e, por isso, infans pode designar a criança no sentido ordinariamente reservado a puer. Na verdade, há usos de infans referindo-se a pessoas de até, pelo menos, quinze anos, com o qual devemos entender que infans não remete especificamente à criança pequena que não adquiriu ainda a capacidade de falar, mas que, antes, refere-se aos que, por sua minoridade, não estão ainda habilitados para testemunhar nos tribunais: infans seria assim "o que não pode valer-se de sua palavra para dar testemunho". A palavra infantes também passa a designar a muitas outras classes de marginais que não participam da atividade pública, como os doentes mentais. (disponível em: http://www.scielo.br/pdf/ep/v29n1/ao2v29n1.pdf). (os destaques finais, em itálico, são nossos).
} 
Assim, o homem é um animal cívico, mais social do que as abelhas e os outros animais que vivem juntos. A natureza, que nada faz em vão, concedeu apenas a ele o dom da palavra, que não devemos confundir com os sons da voz. Estes são apenas a expressão de sensações agradáveis ou desagradáveis, de que os outros animais são, assim como nós, capazes. A natureza deu-lhes um órgão limitado a este único efeito; nós, porém, temos a mais, senão o conhecimento desenvolvido, pelo menos o sentimento obscuro do bem e do mal, do útil e do nocivo, do justo e do injusto, objetos para a manifestação dos quais nos foi principalmente dado o órgão da fala. Este comércio da palavra é o laço de toda sociedade doméstica e civil (ARISTÓTELES, 1988, Livro I, cap. 2, p. 1253).

É por meio da fala que os homens se diferem dos outros animais e escravos. É apenas com o uso da fala que é possível a existência de uma comunidade de iguais. Um ser dotado de logos é capaz de compreender o que outro ser fala. Esse é o princípio de uma comunicação entre iguais. Somente os homens dotados de fala conseguem se comunicar.

Rancière nunca deixará de nos lembrar que no seio da filosofia política e, especificamente da democracia, habita a aporia, uma dificuldade própria e insolúvel do próprio pensamento. Refere-se ainda a Aristóteles, como sendo o primeiro a tratar da união entre filosofia e política e também evidenciar a aporia própria desses casos. Escreve: "Aristóteles nos indica isso numa frase que é um dos primeiros encontros entre o substantivo 'filosofia' e o adjetivo 'política' [a saber]: 'Do que há igualdade e do que há desigualdade, a coisa leva à aporia e à filosofia política" (RANCIÈRE, 1996a, p. 11), porque segundo o filósofo, “a filosofia torna-se 'política' quando escolhe a aporia ou o embaraço próprio da política" (RANCIÈRE, 1996a, p. $11)$.

A aporia citada aqui, surge quando problematizamos os ditos possuintes de logos e os apenas possuintes de voz, com isso, a aporia que surge daí, Rancière diz que é em função da distribuição de partes de uma comunidade: "aqueles supostamente apenas dotados de voz, os escravos, são capazes de compreender o comando daqueles possuintes da fala". Rancière interroga: "como pode alguém compreender o que desconhece?" (RANCIÈRE, 1996a). O fato de o escravo, carente de palavra, unicamente possuidor de voz, compreender o que um ser dotado de fala, possuinte de logos ordena, já faz com que exista algo em comum, inimaginável até então. Há algo que iguala escravos e homens livres. É desse tipo de aporia, segundo Rancière, da qual trata a filosofia política.

Vale ainda lembrar que Rancière não concebe a filosofia política com um ramo natural da árvore filosofia ${ }^{3}$. Para ele, a filosofia torna-se política justamente por essa aporia presente na política. A política passa a ser então, um objeto da filosofia. Mas

\footnotetext{
${ }^{3}$ Referente aos ramos da árvore filosofia atribuída por Descartes.
} 
o que o filósofo entende por filosofia política? Para nosso filósofo, ela é "a atividade que tem por princípio a igualdade, e o principio da igualdade transforma-se em repartição das parcelas de comunidade ao modo do embaraço: de quais coisas há e não há igualdade entre quais e quais? (RANCIĖRE, 1996a, p. 11), e ainda, "O que são esses "quais", quem são esses "quais"“? De que modo a igualdade consiste em igualdade e desigualdade? "(RANCIÈRE, 1996a, p. 11)". É dessa aporia que trata a filosofia política, e para que tal encontro seja produtivo, [o da filosofia com a política], é preciso achar seu ponto de desentendimento. Mas o que é tal desentendimento?

Por desentendimento, Rancière se refere a um tipo determinado de situação de palavra, "aquela em que um dos interlocutores ao mesmo tempo entende e não entende o que diz o outro" (RANCIÈRE, 1996a, p. 12). Não é o desentendimento entre duas pessoas que dizem coisas diferentes, ao contrário, é o conflito entre aqueles que dizem a mesma coisa, mas não dão a mesma significação para essas coisas. Para melhor entender, Rancière vai afirmar que "é o conflito entre aquele que diz branco e aquele que diz branco, mas não entende a mesma coisa, ou não entende de modo algum que o outro diz a mesma coisa com o nome de brancura" (RANCIÈRE, 1996a, p. 12). Não pode de maneira alguma sem entendido como sinônimo de desconhecimento. Por desconhecimento, uma das partes, ou ambas, por ignorância não sabe o que o outro diz. Também não é tampouco um simples "mal-entendido produzido pela imprecisão das palavras" (RANCIÈRE, 1996a, p. 12).

Os casos de desentendimento são aqueles no qual "a disputa sobre o que quer dizer falar constitui a própria racionalidade de situação de palavra (RANCIÈRE, 1996a, p. 12)". Não é um caso da filosofia da linguagem, onde a imprecisão das palavras causa um mal-entendido. No caso do desentendimento, os interlocutores entendem e não entendem aí a mesma coisa nas mesmas palavras. Há uma série de fatores para que isso ocorra, pois, embora alguém entenda o que o outro diz, esse não vê o objeto do qual o outro lhe fala, ou então "porque ele entende e deve entender, vê e quer fazer ver um objeto diferente sob a mesma palavra, uma razão diferente no mesmo argumento" (RANCIÈRE, 1996a, p. 12).

Um caso que pode ser ilustrado aqui é a famosa máxima que diz respeito à justiça; ela [a justiça] consiste em dar a cada um o que lhe é devido. Evidentemente, o conceito de justiça não é interpretado da mesma forma, e não só por conta da significação da palavra, as ações daqueles que a entendem também difere. "As estruturas de desentendimento são aquelas em que a discussão de um argumento remete ao litígio acerca do objeto da discussão e sobre a condição daqueles que o constituem como objeto". Logo é perceptível que o desentendimento não diz respeito apenas as palavras, mas também a própria situação daqueles que falam.

Em busca de esclarecer a composição de tal conceito, Rancière põe luz sobre algo que para nós, que estamos habituados com a definição de democracia como 
"poder do povo", passa despercebido. Ele nos mostra quem era o "povo" na Grécia, quem é o demos que está na base da democracia:

A democracia é o poder do povo, do demos. Mas o que se entende exatamente sob esse nome? O demos, em Atenas, é constituído primeiramente pelos pobres. Mas os pobres não é simplesmente uma categoria econômica, relacionada a um nível de recursos; é bem mais uma categoria simbólica, uma posição no mundo daquilo que se vê e se considera: pobres são as pessoas reles, as que não possuem nada, nenhum título para governar, nenhum título de valor a não ser o fato de terem nascido ali e não alhures [...]. Significa que governam especificamente os que não têm nenhum título para governar (RANCIÈRE, 1996b, p. 370).

Isso porque faz parte da democracia qualquer um (com exceção, é claro, daqueles já nominados) que seja livre: pelo simples fato de ter nascido em tal polis, e especialmente na polis ateniense, depois que a escravidão por dívidas foi abolida. Qualquer um desses corpos falantes fadados ao anonimato do trabalho e da reprodução, desses corpos falantes que não têm mais valor do que os escravos - e menos até, já que diz Aristóteles, o escravo recebe sua virtude da virtude de seu senhor -, qualquer artesão ou comerciante é contado nessa parte da polis que se chama "povo" como participante dos negócios comuns enquanto tais (Cf. RANCIÈRE, 1996a).

Ao trazer à tona que o povo, inicialmente, era composto de uma parcela das pessoas "reles" que habitavam um lugar, justamente aquelas que não tinham parte alguma nem títulos para governar, Rancière evidencia que em sua base, a democracia é um escândalo: um ato escandaloso para o pensamento. $\mathrm{O}$ escândalo está no fato de a democracia ser uma ruptura, inaugurar uma cisão na ordem das coisas, do ponto de vista da legitimidade e da dominação.

Desse modo, o povo nada mais é que a massa indiferenciada daqueles que não têm nenhum título positivo - nem riqueza, nem virtude - mas que, no entanto, têm reconhecida a mesma liberdade que aqueles que os possuem. O demos é condição de efetividade para a política, Rancière (1996b) vai afirmar que "a política existe quando a ordem natural da dominação é interrompida pela instituição de uma parcela dos sem-parcela”. Para o filósofo:

[A] democracia não é um regime político, no sentido de uma forma constitucional, nem mesmo um modo de vida ou a cultura do pluralismo e da tolerância. A democracia é, propriamente dizendo, a instituição simbólica do político na forma do poder daqueles que não são designados a exercer o poder - uma ruptura na ordem da legitimidade e da dominação. A democracia é o poder paradoxal 
daqueles que não contam: a contagem daqueles que não são contados (RANCIÈRE, 2000, p. 124).

A democracia em Rancière pode ser entendida por meio da ação política e da verificação da igualdade ${ }^{4}$ pretensamente existente entre os indivíduos, configurando-se como outra forma de montar a cena política, "ao produzir diferentes relações entre palavras, os tipos de coisas que elas designam e os tipos de práticas que desenvolvem" (RANCIÈRE, 2010a, p. 54). É na democracia que se efetua, de fato, a igualdade que é fundamental para entender a política de Rancière. Tratase, pois, de nos aproximarmos da concepção de igualdade produzida por Rancière, talvez, uma das noções mais intrigantes, tanto do ponto de vista pedagógico quanto político, como mostraremos. Daí podermos afirmar que Rancière amplia o escândalo da democracia com suas afirmações sobre a igualdade. Segundo o filósofo:

A política, em última instância, repousa sobre um único princípio, a igualdade. Só que esse princípio só tem efeito por um desvio ou uma torção específica: o dissenso, ou seja, a ruptura nas formas sensíveis da comunidade. Ele tem efeito ao interromper uma lógica da dominação suposta natural, vivida como natural. Esse efeito é a instituição de uma divisão ou de uma distorção inicial. Essa distorção é que é testemunhada pelas palavras aparentemente muito simples: demos e democracia (RANCIÈRE, 1996b, p. 370).

Na visão de Rancière, a essência da democracia é a pressuposição da igualdade das inteligências, atributo a partir do qual se desdobram as mais ferrenhas reações de seus adversários. Como visto anteriormente, a ideia de uma democracia nunca foi tratada com a melhor forma de governo possível, pois nem todos estariam aptos a governar. As reações adversas à democracia surgem pelo motivo de que os detentores de títulos não aceitam ser considerados como seres iguais aos que não possuem títulos. Assim, parece que se torna possível afirmar que se a igualdade é um a priori da democracia, o ódio a ela é um dos seus a posteriores.

A fim de elaborar a resposta para a questão acerca da especificidade da política, Rancière faz a distinção de dois conceitos, o de política e o de polícia. Mostra que o que se entende na maioria das vezes pelo conceito de política é o consentimento das coletividades, algo para manter a ordem, para entrar em um determinado acordo. Rancière propõe chamar essas práticas pelo conceito de polícia. Com isso, aquilo que era entendido como política, o modo de tentar colocar uma determinada ordem, um determinado consenso entre as pessoas, os modos de ser, ver e fazer numa comunidade é próprio dessa polícia.

\footnotetext{
${ }^{4} \mathrm{O}$ conceito de igualdade é bastante caro para Rancière. Ele trata disso com maior ênfase em seu livro $O$ mestre Ignorante, todavia tal conceito se faz presente em todo seu pensamento político. A afirmação e verificação deste principio de igualdade é o que faz ser possível a existência de da própria política e por conseguinte, da democracia. É a partir da afirmação dessa igualdade que é primeira que se reivindica reconhecimento, que gera o dissenso, ou seja o desentendimento.
} 
Nessas práticas não há política, portanto, nem democracia. Para o filósofo a democracia se traduz pela ação política que confronta e perturba a ordem consensual de funcionamento do Estado, que é a ordem policial que não faz nada mais do que dividir, organizar e ordenar. Somente quando as divisões da ordem policial são desfeitas é que a atividade política é instaurada. Para Rancière (2010, p. 45),

[...] a atividade política é sempre um modo de manifestação que desfaz as divisões sensíveis da ordem policial mediante colocação em ato de um suposto que por princípio lhe é heterogêneo, o de uma parte dos que não tem parte, a que, em última instância, manifesta em si mesma a pura contingência da ordem, a igualdade de qualquer ser falante com qualquer outro ser falante.

Algo próprio dessa polícia é então a distribuição sensível dos corpos em comunidade. Mas o que sobra para a política? A ela cabe justamente criar desordem, perturbar a ordem da polícia por meio de um conjunto de atividades no qual está pressuposto algo inteiramente heterogêneo a polícia, mas que é inerente a cada ser humano, ainda que não esteja inscrito diretamente na ordem social. Tal pressuposição é "a igualdade de qualquer ser falante com qualquer outro ser falante", a qual só pode ser manifestada pelo "dissenso, no sentido mais originário do termo: uma perturbação no sensível, uma modificação singular do que é visível, dizível e contável" (RANCIÈRE, 1996b, p. 372).

Assim, o princípio da igualdade que está na base da política só pode ser verificado por meio da lógica do desentendimento. Ela é a instauradora da política, é essa lógica que efetua o princípio de igualdade. Mas, para que essa igualdade tenha qualquer tipo de eficácia, ela deve ser continuamente argumentada e encenada contra a pressuposição policial da desigualdade. De acordo com Rancière, existe política quando a lógica promovida pelas divisões desiguais ou a ordem da dominação, tida como natural, são derrubadas por lutas e conflitos empenhados na atualização do princípio de igualdade.

O desentendimento político se dá quando surge uma parte que antes não era considerada como aceita, reivindicando algo que lhe é próprio, a igualdade. Podemos afirmar que política para Rancière não é uma relação de poder, mas sim uma relação de mundos. A partir de dois mundos diferentes, dos que tem parcela para com os "sem-parcela", é que de fato ocorre o dissenso e, por fim, a política. É através da existência desta parte dos sem parte, desse nada que é tudo, que a comunidade existe como comunidade política, quer dizer, dividida por um litígio fundamental, por um litígio que se refere à conta de suas partes, antes inclusive de referir-se aos seus 'direitos'.

A política é o momento de questionamento sobre a ordem estabelecida, quando aqueles que não são contados, reconhecidos e sem direito de fala, declaram- 
se iguais perante os padrões de dominação. Rosa Parks ${ }^{5}$ ao se recusar, em 1955, dar seu lugar no ônibus, por causa da segregação racial, estava impondo-se politicamente contra uma ordem que separava negros e brancos de forma desigual. Enfim, o que Rancière define como democracia é a ideia de um demos tomando as ruas e reivindicando aquilo que ainda não tem, questionando a forma como os corpos são postos, como estão estabelecidos. Para ele:

[...] democracia é o nome de uma interrupção singular dessa ordem dos corpos em comunidade que nos propusemos conceituar sob o conceito ampliado de polícia. É o nome daquilo que vem interromper o bom funcionamento dessa ordem por um dispositivo singular de subjetivação (RANCIÈRE 1996a, p. 102).

$\mathrm{O}$ que se percebe na democracia atual Rancière entende como um Estado modesto. Na definição do filósofo, "o Estado modesto é um Estado que torna a política ausente, que renuncia em suma àquilo que não lhe cabe - o litígio do povo para aumentar a sua propriedade, para desenvolver os processos de sua própria legitimação" (RANCIÈRE, 1996a, p. 112-114). Isso causa então, o dano democrático. O dano democrático busca conduzir o litígio à forma de um consenso social, a partir daí começariam as "parcerias" entre os patrões e os empregados.

O desentendimento é então a única forma de existir política e de fato a efetivação da democracia. A negação desse desentendimento, que é o consenso, faz com que não exista uma política e sim uma polícia encarregada apenas de manter a ordem. De acordo com Rancière, dificilmente haverá um governo que possa ser concebido como de fato democrático, porque a democracia é sempre o que está aquém e além do governo: aquém, porque somente a partir da percepção de que todas as pessoas são efetivamente iguais e que todos os títulos e hierarquias se fundam nessa igualdade; além, porque a democracia é o constante questionamento desses títulos, o elemento desestabilizador e perturbador da ordem posta.

\footnotetext{
${ }^{5}$ Em Montgomery, capital do Alabama, as primeiras filas dos ônibus eram, por lei, reservadas para passageiros brancos. Atrás vinham os assentos nos quais os negros podiam sentar-se. No dia $1^{\circ}$ de dezembro de 1955, Rosa Parks tomou um desses ônibus a caminho do trabalho para casa e sentou-se num dos lugares situados ao meio do ônibus. Quando o motorista - branco - exigiu que ela e outros três negros se levantassem para dar lugar a brancos que haviam entrado no ônibus, Parks se negou a cumprir a ordem. Ela continuou sentada e, por isso, foi detida e levada para a prisão. O protesto silencioso de Rosa Parks propagou-se rapidamente. O Conselho Político Feminino organizou, a partir daí, um boicote de ônibus urbanos, como medida de protesto contra a discriminação racial no país. Martin Luther King Jr. foi um dos que apoiou a ação. O ativista e músico Harry Belafonte lembra-se como sua vida mudou, após o dia em que King o chamou por telefone para pedir apoio à ação da mulher que ficou conhecida como a "mãe dos movimentos pelos direitos civis" nos EUA. "A atitude de Rosa Parks nos permitiu reagir contra as pressões política e social que caracterizavam nossa sociedade. Quando King me telefonou, me chamando para um encontro, comecei, pela primeira vez, a lutar oficialmente por essa causa. Quando nós nos vimos e falamos sobre seus planos, percebi que a partir dali eu me engajaria no movimento liderado por ele e Rosa Parks. Foi um momento muito importante", lembrou Belafonte. Disponível em http://www.dw.com/pt/1955-rosa-parks-se-recusa-aceder-lugar-a-um-branco-nos-eua/a-340929. Acesso em o8. out. 2018.
} 
Apenas através do desentendimento se pode exercer a política, e de fato levar a cabo a democracia. Porque é por meio do dissenso que se efetua a política; é por conta de perceber a divisão do mundo em parcelas, e lutar para que se efetue o princípio de igualdade, é que se funda a política. O desentendimento faz com que se efetue o princípio de igualdade.

Em seu livro intitulado Ódio à democracia (2014), Rancière afirma que vivemos uma ilusão de democracia. Este é um fenômeno que se inscreve na longa duração histórica, uma vez que os setores privilegiados da sociedade nunca foram de total acordo, ou concordaram com a principal implicação prática do regime democrático na esfera da política: a ausência de títulos para ingressar nas classes dirigentes.

A ideia da democracia grega não foi bem acolhida pelos impérios que os rodeavam, pensavam eles, que tal ideia era inadmissível. Pode-se perceber esse ódio ao pensar que as formas de governo antes da democracia eram pautadas na legitimidade de dois títulos: a filiação humana ou divina - associadas à superioridade de nascença - e a riqueza. A democracia iniciada na Grécia empregava o princípio do sorteio, alterando a lógica vigente ao mudar para o âmbito da aleatoriedade a responsabilidade de legislar e de governar, agora ao alcance de qualquer cidadão da polis, independente de suas posses ou do nome de sua família. Para quem viveu sempre a governar, isso era inconcebível. Pode-se problematizar, a partir disso, os motivos para o ódio.

Ainda sobre a democracia, Rancière questiona os princípios do modelo democrático representativo, invenção moderna que se vale de uma nomenclatura considerada paradoxal pelo autor, haja vista seu distanciamento em relação à democracia dos antigos. Para o filósofo,

A representação nunca foi um sistema inventado para amenizar o impacto do crescimento das populações. Não é uma forma de adaptação da democracia aos tempos modernos e aos vastos espaços. É, de pleno direito, uma forma oligárquica, uma representação das minorias que têm título para se ocupar dos negócios comuns (RANCIÈRE, 2014, p. 69).

\section{Considerações finais}

Por fim, é possível pensar com Rancière que a democracia representativa na qual estamos inseridos quem acaba governando não é o povo. $\mathrm{O}$ fato é que o povo que ousa fazer valer sua soberania sempre foi um dos maiores medos dos governos ditos democráticos. Essa é, aliás, a razão principal do ódio. O ódio à democracia advém de sua própria natureza, uma vez que o "governo de qualquer um" está permanentemente sob a mira rancorosa daqueles munidos de títulos, seja o nascimento, a riqueza ou o conhecimento. Esses rancorosos utilizam-se de uma ordem policial, e fazem valer o que é decidido por meio de um consenso. Os 
representantes autorizados utilizam-se do recurso policial para que não se efetue a partilha do sensível, para que os sem-parte não atuem politicamente e não se realize a política.

A partir dos escritos que seguiram, tenta-se mostrar que o ódio à democracia não é um mal contemporâneo, mas sim algo que persegue a democracia desde o seu surgimento. Os motivos para tal, como foi apresentado é a não aceitação do demos enquanto participante ativo das decisões (mesmo ainda que seja de forma limitada). O ódio a democracia é entendido então, como um não reconhecimento e não aceitação do principio de igualdade. A democracia é o próprio ato de afirmação de tal princípio, daí as razões do ódio por parte dos que se julgam detentores de títulos.

\section{Referências}

ARISTÓTELES. Política. Trad. Mário da Gama Kury. 2. ed. Brasília: Universidade de Brasília, 1988.

CHAUÍ, M. Convite à filosofia. São Paulo: Ática, 2000.

DAHL, R. A. Sobre a democracia. Tradução de Beatriz Sidou. Brasília: Editora Universidade de Brasília. 2001.

RANCIÈRE, J. O desentendimento. Trad. Ângela Leite Lopes. São Paulo, Editora 34, 1996a. "O desentendimento", in: NOVAES, A. (Org.). A crise da razão. São Paulo:

Companhia das Letras, $1996 \mathrm{~b}$.

. Jacques: o mestre ignorante. 2. ed. Belo Horizonte: Autêntica, 2005.

. Política, policía, democracia. Santiago: LOM Ediciones, 2006.

. A partilha do sensivel: estética e política. São Paulo: EXO Experimental, 2009a.

. O inconsciente estético. Trad. Mônica Costa Netto. São Paulo: Ed. 34, $2009 \mathrm{~b}$.

. El desacuerdo: política y filosofía. Buenos Aires: Nueva Visión, 2010.

. O espectador emancipado. Trad. Ivone C. Benedetti. São Paulo: Martins Fontes, 2012. O ódio à democracia. Trad. Mariana Echalar. São Paulo: Boitempo, 2014.

Submissão: 30.10.2018 / Aceite: 30.11.2018. 